\title{
Optimal treatment of chronic angina in patients with type 2 diabetes mellitus
}

This article was published in the following Dove Press journal:

Research Reports in Clinical Cardiology

7 July 2014

Number of times this article has been viewed

\author{
Harjinder Kaur' \\ Kully Sandhu² \\ Awais Jabbar ${ }^{3}$ \\ Azfar G Zaman ${ }^{3,4}$ \\ 'City Hospitals Sunderland, \\ Sunderland, UK; ${ }^{2}$ University Hospital \\ of North Staffordshire, Stoke- \\ on-Trent, UK; ${ }^{3}$ Freeman Hospital, \\ Newcastle-upon-Tyne, UK; ${ }^{4}$ Institute \\ of Cellular Medicine, Newcastle \\ University, Newcastle, UK
}

\begin{abstract}
Type 2 diabetes mellitus (T2DM) trebles the risk of developing coronary artery disease (CAD); once CAD has developed, the risk of acute coronary syndromes (ACS) and clinical risk associated with a coronary event, both double in diabetic patients. Patients with T2DM have more extensive CAD and present at a younger age; therefore, identification and management of chronic angina in these patients presents an opportunity to limit both cardiovascular symptoms and adverse outcomes. This article reviews the role of screening and treatment for chronic angina in patients with T2DM. There is a strong evidence base for modifying lifestyle as a way of reducing adverse cardiovascular outcomes in the diabetic population and this article reviews evidence of lifestyle modification as an important and necessary adjunct to pharmacologic intervention. Management of chronic stable angina is addressed by looking at treatments that reduce ischemic symptoms and those that reduce adverse cardiovascular outcomes. Trials specific to the diabetic population are limited, with information largely obtained from the diabetic subgroup analysis of large intervention trials. The growing diabetic population with increased propensity to cardiovascular disease mandates trials specifically in this patient population. Revascularization in patients with diabetes is associated with more complications than in the non-diabetic population. Recent trials specific to this population suggest surgical revascularization to be associated with better long-term outcomes and therefore, this article reviews the evidence for the optimal mode of revascularization in this population.
\end{abstract}

Keywords: type 2 diabetes mellitus, chronic angina, cardiovascular disease, coronary revascularization, antianginals

\section{Introduction}

The developed world is in the midst of a worldwide epidemic of diabetes mellitus (DM), with current prevalence estimated at $8 \%$ of the adult population and predicted to at least double over the next 12-15 years with approximately 300 million affected by 2025. ${ }^{1-4}$ Type 2 DM (T2DM) trebles the risk of developing coronary artery disease (CAD); once CAD has developed, the risk of acute coronary syndromes (ACS) and clinical risk associated with a coronary event, both double in diabetic patients. ${ }^{5-8}$ Atherosclerosis is often present at the time of diagnosis of diabetes and as CAD is the leading cause of death in patients with diabetes, prompt diagnosis and risk stratification is of paramount importance in improving outcomes.

A recent report from the American Heart Association reported the widespread prevalence of chronic stable angina in the US. The diagnosis of chronic stable angina is associated with worse health-related quality of life, increased hospitalizations, and adds to the nation's healthcare burden. The presence of chronic stable angina
Correspondence: Azfar G Zaman Freeman Hospital, Freeman Road, High Heaton, Newcastle-uponTyne, Tyne and Wear NE7 7DN, UK Tel +441912137277

Fax +441912231417

Email azfar.zaman@nuth.nhs.uk 
in patients with T2DM is compounded by the presence of more extensive coronary atherosclerosis in the latter. ${ }^{10-12}$ Furthermore, the ischemic burden may be higher at the time of first investigation, as patients with T2DM may have symptomless angina and it is the extent of ischemia that dictates outcomes, not symptoms. ${ }^{13}$

\section{Chronic angina in patients with DM}

The presence of DM is an independent risk factor for enhancing atherosclerosis, and CAD remains the main cause of morbidity and mortality in the diabetic population. ${ }^{14,15}$ Chronic stable angina is the most common clinical manifestation of CAD, affecting 54 million people globally and over 10 million people in the US, and is defined as onset of typical or atypical reproducible chest pain with physical and emotional stress. The symptoms of angina precipitate with exertion, cold weather, or after heavy meals, and are relieved by rest and/or sublingual nitroglycerine. The increase in the prevalence of $\mathrm{DM}$ and its associated adverse effect on CAD progression and prognosis has created a global health burden.

The clinical presentation of angina in patients with DM is often complicated by the absence of classic symptoms of angina pectoris, and patients may present with dyspnea on exertion or with no symptoms at all in the presence of prognostically significant cardiac ischemia. The presence of cardiac ischemia is of more relevance in assessing prognosis than the presence of symptoms (angina or angina equivalent) and this was clearly demonstrated in the BARI 2D study where 5-year mortality showed no difference in patients with DM and ischemia stratified on the basis of symptoms, angina equivalent, or asymptomatic. Following an episode of acute coronary syndrome, the presence of ischemia is a powerful marker of prognosis in patients with or without DM. ${ }^{16,17}$

\section{Role of screening for CAD in DM}

A substantial percentage of patients with T2DM have silent myocardial ischemia (SMI) as determined by stress testing $(17 \%-59 \%)$, and those individuals with SMI are at greater risk for cardiovascular events. ${ }^{18-20}$

This high prevalence of coronary disease in the diabetic population provides a strong rationale for early screening and aggressive risk factor modulation. However, early clinical detection of myocardial ischemia is challenging as it frequently presents with atypical features and is often clinically silent. ${ }^{21}$ These challenges are compounded by legitimate questions about the utility of the resulting data in guiding patient care.
Cardiovascular CT is an effective rule-out test as a zero calcium score has similar clinical import in both diabetic and non-diabetic populations. ${ }^{22}$ However, the presence of large amounts of calcium can reduce the specificity of CT angiography due to blooming artifacts generated by calcium deposits. ${ }^{23}$ Although this may limit the positive predictive value of cardiovascular CT, its negative predictive value remains high. Stress echocardiography (no ionizing radiation) and single-photon emission computed tomography-myocardial perfusion imaging (SPECT-MPI; ionizing radiation) provide information on wall motion as well as ejection fraction. Stress cardiovascular magnetic resonance (CMR) is a viable alternative ${ }^{24}$ for patients without significant contraindications (permanent pacemakers, severe claustrophobia, large body girth) although there exists a theoretical risk of nephrogenic systemic fibrosis following administration of gadolinium contrast agents in patients with severe renal impairment (estimated glomerular filtration rate $<30 \mathrm{~mL} / \mathrm{m}^{2}$ ), but this risk is reduced with modern preparations. $^{24}$

There is evidence that certain biomarkers could be used for risk prediction of ischemic events in T2DM. ${ }^{25-28}$ Of particular interest, interleukin- 6 and activin A have, in small studies, been independently associated with cardiovascular events and mortality in T2DM. ${ }^{29}$ These findings need to be reproduced in larger population sets before being used routinely for risk prediction.

Nevertheless, the current American Diabetic Association (ADA) guidelines counsel against the routine screening of diabetic subjects for coronary disease. ${ }^{30}$ This is in discord with The American College of Cardiology Foundation and the American Heart Association (ACCF/AHA) Guidelines for the assessment of cardiovascular risk in asymptomatic adults, which on the basis of limited observational data, suggest that coronary artery calcium (CAC) scoring may be of utility in risk stratification in asymptomatic diabetic subjects over the age of 40 years. ${ }^{31}$ The impact of such a strategy on outcomes remains to be tested in a prospective randomized trial. Within the UK, such a use of CAC in asymptomatic individuals is not currently recommended. ${ }^{32}$

\section{Management of chronic stable angina and associated risk factors}

For the majority of antianginal agents, there are no specific trials in the diabetic population and information derives from subgroup analyses, which is suboptimal as the diabetic phenotypes are ill-defined. Managing chronic stable angina in patients with DM follows the same principles as those 
for patients without diabetes, namely, controlling ischemic symptoms and reducing ischemic burden. These twin goals of therapy are the same as in the non-diabetic population, and if successfully implemented, should provide symptom relief, improving quality of life and prevent cardiovascular events. In addition, lifestyle changes such as diet, regular exercise, patient education, and revascularization if required provide the third important pillar for the optimal management of chronic stable angina in patients with DM.

The increased morbidity and mortality in patients with DM and CAD coupled with the likely presence of more than one risk factor are compelling reasons for a more aggressive approach to secondary prevention in such patients.

\section{Relief of ischemic symptoms}

Ischemic symptoms can be controlled with beta blockers, nitrates, and/or calcium channel blockers. ${ }^{33}$ These agents decrease myocardial ischemia by decreasing the major determinants of myocardial oxygen demands and/or by increasing coronary blood flow to the ischemic myocardium. Newer antianginal agents have mechanisms related to modulating myocardial metabolism or by inhibiting ion channels. ${ }^{33,34}$ Drugs that are effective in providing symptom relief are discussed below.

\section{Nitrates}

Nitrates provide rapid and effective relief of symptoms through dilatation of epicardial coronary arteries and increasing venous capacitance. The main effect of nitrate is on the preload but its direct effect is more pronounced on afterload in higher doses. This results in a reduction in myocardial oxygen consumption and improves overall exercise capacity. Nitrates react with sulfhydryl groups and enzymes (mitochondrial aldehyde dehydrogenase), to produce $S$-nitrosothiol and finally nitric oxide (NO), which in turn activates smooth muscle guanyl cyclase to increase the cGMP levels. This results in inhibition of $\mathrm{Ca}^{+2}$ entry into muscle cells and relaxation of muscle filaments. Similarly, NO also activates platelet cGMP, which reduces intra-platelet calcium concentrations and partially impairs platelet activation. ${ }^{35}$ The presence of increased NO also leads to improvement in endothelial function and it can be speculated that this may be of particular benefit to patients with DM who are known to have endothelial dysfunction. Improved endothelial function further contributes to vasodilatation and optimizes vascular reactivity. Finally, nitroglycerin redistributes coronary blood flow (the steal effect) from normally perfused areas of myocardium to ischemic zones. ${ }^{36}$
Various forms of nitroglycerin are available with sublingual having the most rapid onset of action (1-3 minutes) and being more reliable. This also acts as a "diagnostic test" for angina and should be prescribed for every patient unless contraindicated. Long- and short-acting formulations are used and increased gradually as tolerated, if needed. Tolerance may develop within 12-24 hours, and can be avoided through implementation of a nitrate-free period of 8 hours each day. Nitroglycerin can be used prophylactically when angina can be expected, such as activity after a meal, emotional stress, sexual activity, and in colder weather. ${ }^{37,38}$

\section{Nicorandil}

Nicorandil is a nicotinamide derivative with a nitrate moiety and has a dual mechanism of action. It increases potassium ion conductance by opening ATP-sensitive potassium channels, which in turn activates the enzyme guanylate cyclase. Second, due to its nitrate content, it causes smooth muscle relaxation, thereby reducing afterload and also lowers preload through venodilatation and promotes expression of endothelial NO synthase.

In patients with chronic stable angina, nicorandil is associated with improved myocardial function during ischemia. ${ }^{39}$ The IONA (Impact of Nicorandil in Angina) study of nicorandil against placebo in patients on optimal antianginal treatment showed a significant improvement in outcome due to a reduction in major coronary events with nicorandil in patients with stable angina, resulting in a $17 \%$ reduction in hospitalization for chest pain, MI, and CAD death. ${ }^{40}$

\section{Beta blockers}

Beta adrenergic receptors are a class of $\mathrm{G}$ proteincoupled receptors, and are stimulated by catecholamines and mediated by adenyl cyclase. $\beta_{1}$ receptors cause increased heart rate, contractility, automaticity, and conduction velocity. Therefore, specific $\beta_{1}$ antagonists lower heart rate both at rest and exercise, contractility, and blood pressure, thereby reducing myocardial oxygen demand. In addition, due to their negative chronotropic effect, beta blockers prolong diastole, raising coronary artery blood flow and myocardial perfusion.

There is evidence for prognostic benefits from the use of beta blockers in post-MI and heart failure patients. Whilst data in stable CAD patients are lacking, extrapolation from these data together with retrospective analysis suggests that these drugs may be beneficial as first line antianginal therapy in stable CAD patients without contraindications. ${ }^{41}$ Beta blockers are effective in improving prognosis in post-MI 
patients with DM by reducing the likelihood of re-infarction, sudden death, and ventricular arrhythmias. ${ }^{42,43}$

Although some beta blockers may have negative metabolic effects by increasing insulin resistance and masking hypoglycemic symptoms, overall, the positive effects of beta-blockade on prognosis outweigh the negative glucometabolic effects. There appears to be a difference between non-vasodilating, $\beta$ 1-antagonists (eg, metoprolol and atenolol) and beta blockers with vasodilating properties (eg, the $\beta / \alpha$-adrenoblockers carvedilol and labetalol, and $\beta 1$ blockers with modulation synthesis of NO, nebivolol), with the latter advocated as having a better glucometabolic profile. ${ }^{44}$

\section{Calcium channel blockers}

Calcium channel blockers (CCB) are efficacious in relieving ischemic symptoms, and verapamil and diltiazem may prevent reinfarction and death. ${ }^{45,46} \mathrm{CCBs}$ bind to and inhibit L-type calcium channels, reducing calcium influx into cells leading to relaxation of smooth muscle cells and vasodilatation of peripheries and coronary vasculature. There are two types of CCBs: 1) non-dihydropyridine: these drugs (verapamil and diltiazem) are less selective and lower heart rate by slowing sinoatrial (SA) and AV nodal conduction and depressing myocardial contractility. Due to their negative inotropic effect, they are avoided in post complex MI and in uncompensated heart failure; 2) dihydropyridine: this class of drug (amlodipine; nifedipine; felodipine; isradipine; nicardipine; nisoldipine) lowers BP and myocardial wall tension, thereby reducing myocardial oxygen consumption. Their vasodilatory effect increases coronary blood flow and improves the myocardial oxygen imbalance that causes angina. ${ }^{47}$ In doing so, these drugs have been shown to reduce angina frequency, nitrates usage, and extend exercise tolerance through a reduction in ischemic changes on treadmill and ECG ${ }^{47-49}$ Amlodipine, in particular, has independent action in relieving diastolic dysfunction other than a reduction in BP. ${ }^{50}$ All drugs in this class have the potential to cause reflex tachycardia which can be blunted with adjunct use of beta blockers. They can also replace beta blockers, if not tolerated or where they are contraindicated as in severe obstructive airways disease.

\section{Ranolazine}

Ranolazine is an inhibitor of the late sodium channel current with antianginal effects and has the additional benefit of improving glycemic control. ${ }^{51}$ Ranolazine has been shown to decrease angina in stable CAD in randomized, doubleblind trials as a monotherapy (MARISA [Monotherapy
Assessment of Ranolazine in Stable Angina] trial), ${ }^{52}$ or in combination with a beta blocker or calcium channel blocker (CARISA [Combination Assessment of Ranolazine in Stable Angina] and ERICA [Efficacy of Ranolazine in Chronic Angina] trials). ${ }^{53,54}$ In two substudies, ranolazine decreased hemoglobin $\mathrm{A}_{1 \mathrm{c}}\left(\mathrm{HbA}_{1 \mathrm{c}}\right)$ levels in patients with DM treated for chronic angina for 12 weeks (CARISA trial) or ACS for 4 months (MERLIN-TIMI 36 [Metabolic Efficiency With Ranolazine for Less Ischemia in Non-ST-Elevation Thrombolysis In Myocardial Infarction-36]). ${ }^{55}$ Thus, ranolazine may be particularly well suited for treating CAD in patients with DM. In the only prospective study of patients with angina and DM, Kosiborod et $\mathrm{al}^{56}$ performed an international, doubleblind trial in 949 CAD patients with type 2 DM and stable angina treated with one or two antianginal drugs (TERISA study). Patients were randomized to 8 weeks of treatment with ranolazine versus placebo and those treated with ranolazine had fewer episodes of angina (3.8 vs 4.3 episodes/week) and less use of sublingual nitroglycerin (1.7 vs 2.1 doses/week) from weeks 2 to 8 compared with placebo. The benefits of ranolazine were more prominent in patients with higher $\mathrm{HbA}_{1 \mathrm{c}}$, with a statistically significant interaction at several different cut-points for $\mathrm{HbA}_{1 \mathrm{c}}$. This study provided clear evidence that addition of ranolazine decreased the frequency of episodes of angina and nitroglycerin use in patients with type 2 DM. The results confirmed prior post hoc analyses of subgroups from the CARISA ${ }^{54}$ and MERLIN-TIMI $36^{55}$ trials, thus providing corroborative evidence in a prospective trial. It should be noted, however, that this was a short-term (8-week) study with the major limitation being that the absolute effects, although statistically significant, were small. Ranolazine resulted in only 0.5 fewer episodes of angina and 0.4 fewer sublingual nitroglycerin tablets used per week, and disappointingly, quality of life measures were not statistically significantly altered. Whilst the clinical relevance of such slight absolute differences may be questioned, the findings in this stable CAD population provided proof of concept that ranolazine, with a unique mechanism of action, is beneficial, can be added to other established antianginal drugs, and is particularly effective with higher $\mathrm{HbA}_{1 \mathrm{c}}$ levels. This is especially relevant for CAD patients with $\mathrm{DM}$, who may have more limited benefits from revascularization and rely to a greater extent on medical management.

The mechanism(s) for why ranolazine had greater benefits in patients with higher $\mathrm{HbA}_{1 \mathrm{c}}$ levels is as yet, unknown. Improvement of endothelial function in patients with poorer control of DM and more severe CAD may be contributory as ranolazine improved endothelial function in a small study 
of patients with DM. ${ }^{57}$ The benefits of ranolazine may be related to glucose metabolism, or raising the threshold for angina. Although decreasing angina frequency and duration, both important in improving quality of life, future studies will need to establish whether ranolazine also reduces myocardial ischemia, as this is a powerful determinant of outcomes and prognosis. The TERISA study is the first trial showing a differential and beneficial effect on angina in patients with DM; however, further studies will be required to confirm if ranolazine has preferential benefits in DM that are related to this drug class by inhibiting the late sodium channel current and/or improving glycemic control. This would help to determine the appropriate combination of drugs and to design new therapies that specifically target CAD in patients with DM.

\section{Ivabradine}

This is a specific, heart-rate-lowering, antianginal drug that works through inhibiting the $\mathrm{I}_{\mathrm{f}}$ current - the primary modulator of spontaneous diastolic depolarization in the sinus node. Ivabradine is indicated in the treatment of chronic stable angina in patients with a contraindication or intolerance to beta blockers, or in combination with beta blockers if the patient remains symptomatic or has a heart rate $>70 \mathrm{bpm}$, especially if there is also left ventricular (LV) dysfunction. It can be used in selected patients with intolerance or contraindication to beta blockers. High heart rate is associated with a worse outcome in patients with $\mathrm{DM}^{58}$ and ivabradine is effective in preventing angina in these patients without any safety concerns or adverse effects on glucose metabolism. ${ }^{58-60}$ The BEAUTIFUL ${ }^{61}$ (ivabradine for patients with stable coronary artery disease and left-ventricular systolic dysfunction) trial showed that ivabradine decreased the chances of MI as well as the need for revascularization in stable chronic angina. However, there was no direct evidence related to improvement of angina in the diabetic population.

\section{Trimetazidine}

This novel drug (a mitochondrial enzyme, 3-ketoacyl coenzyme A thiolase [3-KAT] inhibitor) is a metabolic modulator that improves myocardial energetics at several levels. ${ }^{62}$ Trimetazidine increases myocardial glucose utilization, minimizes free radical production, and protects against intracellular calcium overload and acidosis. The Trimetazidine in Angina Combination Therapy (TACT) study ${ }^{63}$ confirmed the safety of adding trimetazidine to ongoing therapy, resulting in increased exercise tolerance with lower angina frequency. However, no direct evidence is available for its effective use in the diabetic population.

\section{Prevention of adverse cardiovascular events}

In patients with chronic stable angina, the main determinants of adverse outcomes are those related to thrombotic events and onset or progression of ventricular dysfunction. The goals of therapy are therefore to stabilize plaque and prevent progression and prevent or reduce damage from plaque rupture and thrombotic complications. Preventive management includes lifestyle modification, pharmacologic intervention, and appropriate revascularization in individuals with ischemic myocardium.

\section{ACE inhibitors}

ACE inhibitors are effective in improving mortality and morbidity both in symptomatic and asymptomatic angina in diabetic patients. All patients with DM and stable $\mathrm{CAD}$ are recommended an ACE- ${ }^{64}$ largely on the basis of the Heart Outcomes Prevention Evaluation (HOPE) study, which showed a $25 \%$ reduction in $\mathrm{MI}$, stroke, or cardiovascular death for patients with known vascular disease or DM randomized to placebo or ramipril. This finding was consistent in the pre-specified subgroup of patients with DM. ${ }^{65}$

A proportionately similar trend to benefit was observed in the subgroup of patients with DM in the EURopean trial On reduction of cardiac events with Perindopril in stable coronary Artery disease (EUROPA) trial with perindopril in stable $\mathrm{CAD}$, which recruited a population at lower cardiovascular risk. ${ }^{66}$ The Ongoing Telmisartan Alone and in Combination With Ramipril Global Endpoint (ONTARGET) trial compared ramipril and the angiotensin receptor blocker, telmisartan in a high-risk population similar to that in HOPE. In this head-tohead comparison, telmisartan was found to be equivalent to ramipril as regards to the primary outcome - a composite of death from cardiovascular causes, MI, stroke, or hospitalization for heart failure - while a combination of the two drugs caused adverse events without any increase in benefit. ${ }^{67}$

On the basis of this study, it is reasonable to use either ACE-I or ARBs in patients with CAD and DM; however, a combination of the two drugs should be avoided. Some small studies have shown ACE inhibitors to enhance the hypoglycemic effects of oral hypoglycemic agents, ${ }^{68,69}$ but these preliminary findings have not been reproduced in larger cohorts of patients.

\section{Lipid-lowering therapy}

All lipoprotein classes are deranged in T2DM with the two core components affected being a moderate elevation of fasting and non-fasting triglycerides (TGs) and low HDL-C. 
Other features comprise elevations of TG-rich lipoprotein (TRLs), including chylomicron and VLDL remnants, which are small dense LDL particles. A wealth of data from case-control, mechanistic, genetic, and large observational studies indicate that a causal association exists between elevation of triglyceride-rich particles and their remnants, low HDL-C, and CVD risk. ${ }^{70,71}$ Data from statin trials strengthen the position of low HDL as an independent CVD risk marker, even in patients with an LDL-C level that is not elevated. ${ }^{72,73}$ Data from the Fenofibrate Intervention and Event Lowering in Diabetes (FIELD) and ACCORD (Action to Control Cardiovascular Risk in Diabetes) studies demonstrated that cardiovascular event rates were significantly higher in those with dyslipidemia (LDL-C: $2.6 \mathrm{mmol} / \mathrm{L}[100 \mathrm{mg} / \mathrm{dL}], \mathrm{TG} \geq 2.3 \mathrm{mmol} / \mathrm{L}, \mathrm{HDL}-\mathrm{C}$ : $\leq 0.88 \mathrm{~mol} / \mathrm{L}) \cdot{ }^{74,75}$ In a 5 -year follow-up of the FIELD study, ${ }^{76}$ the baseline variables best predicting CVD events were lipid ratios (non-HDL/HDL-C and total/HDL-C). Although Apo $\mathrm{B}-\mathrm{Apo} \mathrm{A}$ is related to CVD outcomes, this ratio was not superior to traditional lipid ratios.

Comprehensive and consistent data exist on the mechanism of action and efficacy of statins in the prevention of CVD events in T2DM. ${ }^{77}$ The benefits of statin therapy in lowering LDL-C and reducing CVD events are seen in all subgroup analyses of major randomized controlled trials (RCTs) ${ }^{78}$ In a meta-analysis of 14 RCTs covering 18,686 people with DM, with a mean duration of follow-up 4.3 years and 3,247 major vascular events, a 9\% reduction in all-cause mortality and a $21 \%$ reduction in the incidence of major vascular outcomes was reported per mmol/L of LDL-C lowering (RR: 0.79; 99\% confidence interval $[\mathrm{Cl}]$ : $0.72-0.87 ; P=0.0001)$. This reduction was similar to that seen in the non-DM population. The magnitude of the benefit was associated with the absolute reduction in LDL-C, highlighting a positive relationship between LDL-C and CVD risk, and was seen at a starting LDL-C as low as $2.6 \mathrm{mmol} / \mathrm{L}^{79}$

Reports from larger RCTs confirm statins to be safe and well-tolerated with the frequency of adverse events, except for muscle symptoms, being rare. In the majority of cases of myopathy or rhabdomyolysis, there are drug interactions with a higher-than-standard dose of statin. ${ }^{80,81}$ The combination of gemfibrozil and statins should be avoided due to pharmacokinetic interaction; however, there are no safety issues with fenofibrate and statins. ${ }^{74}$

A meta-analysis of five statin trials reported that the risk of new onset DM increased with intensive statin (atorvastatin or simvastatin $80 \mathrm{mg}$ daily) therapy (OR: 1.12; 95\% $\mathrm{Cl}: 1.04-1.22 ; I^{2}=0 \%$ ), compared with moderate ( simvastatin $20 \mathrm{mg}$ or pravastatin $40 \mathrm{mg}$ ) doses. ${ }^{82}$ In the intensive group, two additional cases of new-onset DM per 1,000 patient years were observed, whereas the number of CVD events was reduced by 6.5 cases.

\section{Antiplatelet drugs}

Progression of atherothrombosis is accelerated by platelet activation, which is increased in patients with DM. ${ }^{83}$ Increased platelet activation is associated with increased whole blood thrombogenicity ("vulnerable blood") in patients with DM and stable CAD, ${ }^{84,85}$ and is reduced with addition of clopidogrel. ${ }^{86}$ The increased risk of bleeding associated with antiplatelet drugs prevents their widespread use in unselected cohorts of patients with DM and there is no direct evidence of the benefit of aspirin in primary prevention. In patients with DM and stable angina, there is unequivocal evidence of the benefit of long-term, low-dose aspirin in significantly reducing serious vascular events. ${ }^{87}$ There is no evidence for the addition of a second (P2Y12 inhibitor) antiplatelet drug for secondary prevention in stable CAD. For such patients undergoing percutaneous coronary revascularization, the duration of a second agent is determined by the type of coronary stent inserted (1 month for bare metal and 12 months for drug-eluting stents [DES]). Following acute coronary syndromes, the role of an additional antiplatelet agent for 1 year is recommended. ${ }^{88}$

\section{Lifestyle changes}

Risk factors for CAD have a complex relationship with the pathophysiology of the disease. ${ }^{89}$ Patients with two or more risk factors may have up to a 4-fold greater risk of having CAD and those with three risk factors an 8- to 20-fold increased risk of having CAD. ${ }^{90}$ A recent UK Health and Lifestyle Survey reported that modest changes in health behavior could delay aging by 12 years, with a $25 \%$ reduction in the risk of death. ${ }^{91}$ Therefore, identifying risk factors and taking necessary preventive measures can improve prognosis in chronic stable angina. The following is a brief summary of recommendations for lifestyle changes in patients with DM and chronic stable angina (a more detailed description is presented in the addendum).

\section{Patient education}

Patients are strongly recommended to modify lifestyles, such as daily physical activity and reduced intake of saturated fats ( $<7 \%$ of total calories), trans fatty acids $(<1 \%)$, and cholesterol $(<200 \mathrm{mg} / \mathrm{d}){ }^{92,93}$

\section{Smoking cessation}

A stepwise strategy for smoking cessation is recommended by following the "6 As" (Ask, Advise, Assess, Assist, Arrange, and Avoid). 


\section{Weight control}

BMI should be assessed at every visit and patients counseled to maintain BMI between 18.5 and $24.9 \mathrm{~kg} / \mathrm{m}^{2}$. Similarly, waist circumference should be assessed and advised to be $<102 \mathrm{~cm}$ in men and $<88 \mathrm{~cm}$ in women $(<94 \mathrm{~cm}$ and $<80 \mathrm{~cm}$, respectively for Europeans).

\section{Physical activity}

All patients should engage in 30-60 minutes of moderate intensity aerobic exercise at least 5 days per week.

\section{Diet}

Eating a "healthy diet": adhering to four of five important dietary components: ${ }^{94}$

- low sodium intake $<1.5 \mathrm{~g} /$ day;

- sugar sweetened beverage intake $<36$ oz weekly;

- $\geq 4.5$ cups of fruits and vegetables/day;

- $\geq$ three $1 \mathrm{oz}$ servings of fiber-rich whole grains/day;

- $\geq$ two $3.5 \mathrm{oz}$ servings of oily fish/week.

\section{Revascularization - percutaneous coronary intervention versus coronary artery bypass graft surgery}

Revascularization in diabetic patients is challenged by more diffuse atherosclerosis involvement of epicardial vessels, a higher propensity to develop re-stenosis after PCI (percutaneous coronary intervention), saphenous graft occlusion after coronary artery bypass graft surgery (CABG), and inexorable atherosclerotic progression causing de novo stenosis. ${ }^{95}$

These changes result in a higher operative risk and longterm mortality than seen in patients without DM, irrespective of revascularization modality. ${ }^{96}$ Trial evidence on the effect of myocardial revascularization in patients with DM has lagged behind continued development of PCI, CABG, and pharmacological treatments, making it difficult to establish adequate comparisons..$^{97,98}$

The Bypass Angioplasty Revascularization Investigation 2 Diabetes (BARI 2D) trial was a randomized comparison of myocardial revascularization, either with CABG or PCI, versus optimal medical treatment (OMT) in DM patients with stable CAD considered eligible for either PCI or CABG. ${ }^{99}$ Once the most appropriate revascularization technique had been chosen, patients were randomized to OMT alone or to revascularization plus OMT. At 5 years, there were no significant differences in the combined endpoint of death, MI, or stroke between the OMT (12\%) and revascularization (12\%) arms. In the surgical group, freedom from major adverse cardiac and cerebrovascular events (MACCE) was significantly higher with $\mathrm{CABG}(78 \%)$ than with OMT alone
(70\%, $P=0.01)$, but there was no difference in survival (CABG $86 \%$; OMT $84 \% ; P=0.33$ ). In the PCI arm (patients in the PCI group had less extensive CAD than in the CABG group), there were no significant differences in MACCE or survival between PCI and OMT. During subsequent follow-up, 38\% of patients assigned to OMT underwent at least one revascularization for symptomatic relief, compared with $20 \%$ in the revascularization stratum. The study showed that in patients with diabetes and stable $\mathrm{CAD}$, an initial conservative strategy with OMT saved approximately $80 \%$ of interventions over the next 5 years. However, initial coronary revascularization was superior to medical therapy in maintaining freedom from angina, preventing new onset of angina and arresting worsening of angina in diabetic patients during 3 years of followup. ${ }^{100}$ The difference was remarkable, especially during the first year after randomization, but diminished over the period with the revascularization group having significantly lower need for subsequent revascularization over time.

Overall, except in specific situations such as left main coronary artery stenosis $\geq 50 \%$, proximal left anterior descending stenosis, or triple vessel disease with impaired LV function, myocardial revascularization in patients with DM did not improve survival when compared with medical treatment. When extrapolating these results into practice, it is important to remember criteria used to select patients. Patients were excluded if they required immediate revascularization or had left main coronary disease, a creatinine level $>2.0 \mathrm{mg} / \mathrm{dL}$ ( $>177 \mathrm{mmol} / \mathrm{L}), \mathrm{HbA}_{1 \mathrm{c}}>13.0 \%$, class IIIIV heart failure, or if they had undergone PCI or CABG within the previous 12 months.

\section{Percutaneous coronary revascularization versus $C A B G$ surgery}

The literature on CABG versus $\mathrm{PCI}$ in patients with $\mathrm{DM}$ is limited by confounder bias in registries, the ongoing technological development in this field, for example, drug eluting stents, bioabsorbable stents, robotic surgery, and apart from the FREEDOM $^{101}$ (Future Revascularization Evaluation in Patients with Diabetes Mellitus: Optimal Management of Multivessel Disease) and CARDia ${ }^{102}$ (Coronary Artery Revascularization in Diabetes) trials, a lack of prospective RCTs. The result is that much of the available information is derived from subgroup analyses in trials in populations in which patients with DM may be relatively few and/or poorly defined.

Despite these limitations, higher repeat revascularization rates after PCI are consistently reported in DM patients included in RCTs comparing CABG and PCI. A meta-analysis based on individual data from 10 RCTs 7,812 patients) comparing both types of revascularizations 
reported a distinct survival advantage for CABG in DM patients (Figure 1). ${ }^{96}$ The 5-year mortality was 20\% with PCI, compared with $12 \%$ with CABG (OR: 0.7 ; 95\% CI: 0.6-0.9), but interestingly, no difference was found for patients without DM; the interaction between the presence of DM and type of revascularization was significant. The CARDia trial was the first study to compare revascularization strategies specifically in the diabetic population. ${ }^{102}$ The introduction of DES coincided with the enrollment period, leading to a mixed use of bare metal stents (BMS) (31\%) and DES (69\%). After 1 year, there was a non-significantly higher rate of the composite of death, MI, and stroke (driven by a higher rate of $\mathrm{MI}$ ), and significantly higher rates of repeat revascularization in the PCI group $(2 \%$ vs $12 \%, P<0.001)$. The conclusions were challenged by the failure to recruit to target and the trial failed to reach the numbers intended to adequately power the study $(n=510) .{ }^{102}$

In the SYNTAX trial, ${ }^{103}$ only DES (paclitaxel-coating), was mandated and the rate of MACCE after 1 year was twice as high with PCI when compared to CABG. In the pre-specified subgroup with DM, the relative risk for repeat revascularization after 1 year was even higher (RR: 3.2; 95\% CI: 1.8-5.7; $P<0.001)$. In patients with DM and complex lesions giving rise to high SYNTAX scores, 1-year mortality was higher in the

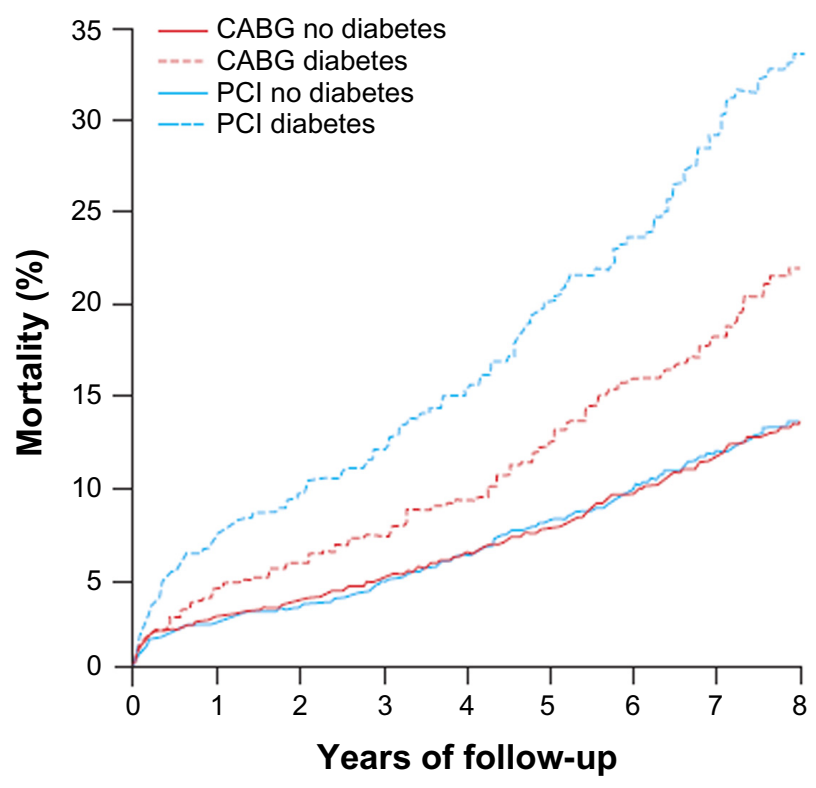

Figure I A meta-analysis of mortality outcomes based on individual data from 10 RCTs comparing both types of revascularizations.

Note: Reprinted from The Lancet, 373, Hlatky MA, Boothroyd DB, Bravata DM, et al, Coronary artery bypass surgery compared with percutaneous coronary interventions for multivessel disease: a collaborative analysis of individual patient data from ten randomised trials, pages 1190-1197.96 Copyright (C) 2009, with permission from Elsevier.

Abbreviations: $\mathrm{PCl}$, percutaneous coronary intervention; $\mathrm{CABG}$, coronary artery bypass graft surgery; RCT, randomized controlled trials.
DES group ( $14 \%$ vs $4 \% ; P=0.04) .{ }^{104}$ After 5 years of follow-up, the rates of MACCE were significantly higher in DM patients undergoing PCI compared to CABG (PCI: 46.5\% vs CABG: $29.0 \% ; P<0.001)$. Qualitatively similar findings were reported for repeat revascularization (PCI: $35.3 \%$ vs CABG: $14.6 \%$; $P<0.001)$. However, there was no difference in the composite of all-cause death/stroke/MI (PCI: 23.9\% vs CABG: 19.1\%; $P=0.26$ ). The conclusion from the study was that, although PCI was a potential treatment option in patients with less complex lesions, $\mathrm{CABG}$ should be the revascularization choice for patients with complex anatomic disease, especially with concurrent DM. ${ }^{105}$

Whilst the results from the SYNTAX trial seemed to provide clarity in the selection of revascularization strategy in patients with DM, in contrast, an analysis of DM patients included in the Angina With Extremely Serious Operative Mortality Evaluation (AWESOME) randomized trial and registry, included high-risk patients for $\mathrm{CABG}$ (prior $\mathrm{CABG}$, recent $\mathrm{MI}$, left ventricular ejection fraction $30 \%$, or intra-aortic balloon pump treatment) showed no significant difference in 3-year mortality between revascularization techniques. ${ }^{106}$ Recent large patient registries report better outcomes in patients with DM treated with $\mathrm{CABG}$, compared with DES, in terms of mortality but at the expense of a higher stroke rate. ${ }^{107}$ An analysis of 86,244 patients $\geq 65$ years of age undergoing CABG and 103,549 patients undergoing PCI from 2004 to 2008 revealed 4-year survival to be significantly higher with surgery, with the association of surgery and improved survival being most marked in insulin-treated DM. ${ }^{108}$ The Revascularization for Unprotected Left Main Coronary Artery Stenosis: Comparison of Percutaneous (MAIN COMPARE) study reported long-term outcomes of 1,474 patients with unprotected left main stenosis, treated with DES or CABG. In this specific setting, a subgroup analysis comparing patients with $(n=507 ; 34 \%)$ and without DM did not reveal significant interactions between treatment outcomes and the presence or absence of DM after adjustment for covariates. ${ }^{109}$

The FREEDOM trial randomized 1,900 patients (majority with three-vessel disease) to treatment with CABG or PCI with any DES after FDA approval. All patients were prescribed currently recommended medical therapies for the control of LDL-C, systolic BP, and $\mathrm{HbA}_{1 \mathrm{c}}$. The primary outcomes measure was a composite of total mortality and non-fatal MI or stroke. After a median of 3.8 years, the primary outcome occurred more frequently in the PCI group $(P=0.005)$, with a 5 -year rate of $26.6 \%$, compared with $18.7 \%$ in the CABG group. The benefit of CABG was driven by differences in 

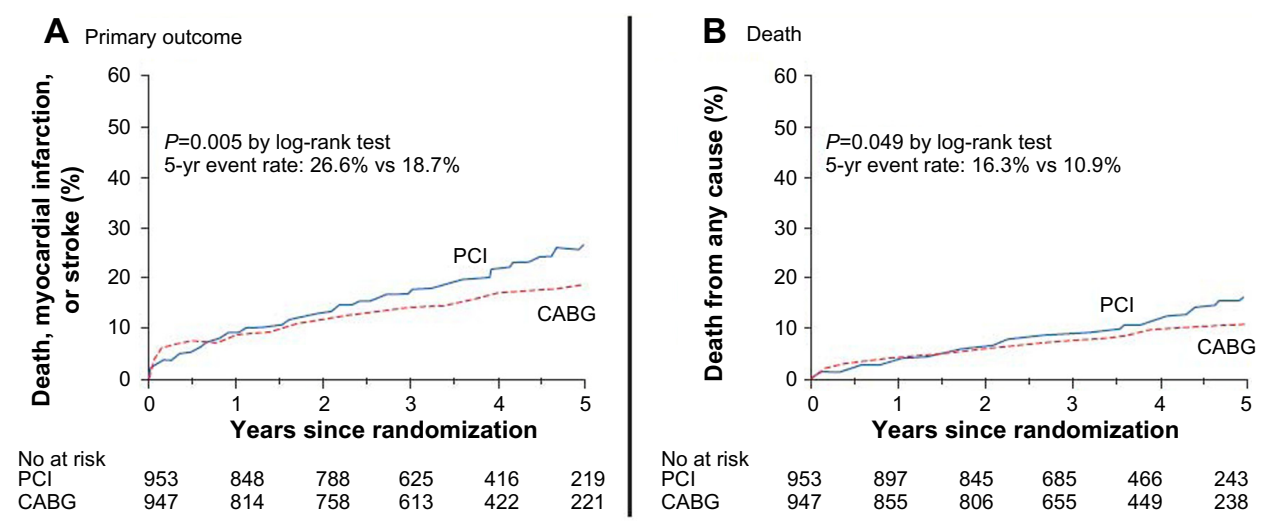

Figure 2 Primary outcomes measure (total mortality, non fatal MI or stroke) (A) and total mortality from the FREEDOM trial (B).

Note: From N Eng J Med, Farkouh ME, Domanski M, Sleeper LA, et al. Strategies for multivessel revascularization in patients with diabetes, volume 367, pages 2375-2384. ${ }^{101}$ Copyright (C) 2012, Massachusetts Medical Society. Reprinted with permission from Massachusetts Medical Society.

Abbreviations: vs, versus; yr, year; No, number; PCI, percutaneous coronary intervention; CABG, coronary artery bypass graft surgery; MI, myocardial infarction; FREEDOM, Future Revascularization Evaluation in Patients with Diabetes Mellitus: Optimal Management of Multivessel Disease.

both MI $(P<0.001)$ and mortality $(P=0.049$; Figure 2$) .{ }^{101}$ A meta-analysis of trials involving revascularization in DM concluded that patients with multi-vessel CAD and diabetes derived greater benefit from surgical revascularization. ${ }^{110}$

\section{Summary}

The clinical presentation of myocardial ischemia in patients with DM can range from typical chest pain to exertional breathlessness to asymptomatic silent ischemia. Given the increased incidence of CAD in patients with DM, it is disappointing that routine screening of patients with DM has not proven to be of benefit. Once ischemia has been diagnosed, its management follows the same principles as in the non-diabetic population, namely symptom control and improving prognosis through reducing ischemic burden. The only pharmacologic agent that appears to have differential (increased benefit) effect on patients with DM and CAD is ranolazine and further studies are required to elucidate the mechanism of this increased benefit. Optimal medical management with a combination of antianginal agents has been proven to control symptoms of angina and in patients with a low ischemic burden, offers equivalent symptom control to revascularization. Lifestyle changes are central to the management of patients with DM and the importance and long-term benefits in controlling the progression of macrovascular disease cannot be overemphasized. Patient involvement and education are vital to success and access to specialist advice on weight loss, diet, and physical training should be addressed at the time of diagnosis. In patients with high ischemic burden or failure of optimal medical therapy, revascularization should be considered. Whilst the data for revascularization continues to evolve, current data suggests that in diabetic patients with multi-vessel CAD and high
SYNTAX scores, surgical revascularization offers the best long-term outcomes.

\section{Addendum}

The ADA and European Association for the Study of Diabetes (EASD) suggest lifestyle as a pioneer measure in the management of DM and reducing risks of CVD. Lipid control plays a crucial role in modifying cardiovascular risk factors, and therefore, reduction of saturated fat, trans fat, and cholesterol intake; along with increased fiber content and weight reduction is recommended to improve the lipid profile in diabetic patients. Statin therapy is recommended where the $\mathrm{CV}$ risk is $>10 \%$ in patients with diabetes. An LDL-C level either $<1.8 \mathrm{mmol} / \mathrm{L}$ or $30 \%-40 \%$ reduction from baseline together with triglyceride levels $<1.7 \mathrm{mmol} / \mathrm{L}$ and HDL-C $>1.0 \mathrm{mmol} / \mathrm{L}$ are the recommended therapeutic goals. ${ }^{30}$

Weight management involves weight reduction in the overweight and obese, and results in favorable effects on BP, dyslipidemia, and glucose metabolism. ${ }^{111}$ Sleep apnea should be carefully assessed and investigated, as this is associated with increased risk in CV mortality and morbidity. ${ }^{12,113}$ Weight reduction or at least stabilization in overweight or moderately obese people remains the important component in a lifestyle program. Bariatric surgery can lead to promising results in long-term weight loss and reduces the incidence of T2DM and subsequent mortality.

The EASD Diabetes and Nutrition Study Group ${ }^{114}$ emphasized an appropriate intake of total energy and a diet rich in fruits, vegetables, wholegrain cereals, and low-fat protein sources to be more important than the precise proportions of total energy provided by major macronutrients with restrictive salt intake. The PREDIMED study ${ }^{15}$ concluded that in a high cardiovascular risk group, a Mediterranean diet with 
extra-virgin olive oil or nuts can reduce the incidence of major cardiovascular events with the following recommended distribution of macronutrients:

- Proteins: 10\%-20\% of total energy.

- Saturated and trans-unsaturated fatty acids: $<10 \%$ of total daily energy, $<8 \%$ if LDL-C is elevated.

- Oils rich in monounsaturated fatty acids: $10 \%-20 \%$ total energy.

- Polyunsaturated fatty acids: up to $10 \%$ of total energy. The total fat should be $<35 \%$ and $<30 \%$ in overweight group, of total energy.

- Carbohydrate: $45 \%-60 \%$ of total energy.

- Dietary fiber: daily consumption of more than servings of fiber-rich vegetables or fruit and more than servings of legumes per week as a minimum requirement for fiber intake.

- Alcohol: if individuals choose to use alcohol, the intake should be a moderate amount (less than one drink per day for adult women and less than two drinks per day for adult men). Here one unit alcohol beverage is defined as $12 \mathrm{oz}$ beer, $5 \mathrm{oz}$ wine, or $1.5 \mathrm{oz}$ distilled spirits, each containing $\sim 15 \mathrm{~g}$ alcohol.

\section{Disclosure}

The authors report no conflicts of interest in this work.

\section{References}

1. Wild S, Roglic G, Green A, Sicree R, King H. Global prevalence of diabetes: estimates for the year 2000 and projections for 2030. Diabetes Care. 2004;27(5):1047-1053.

2. Harris MI. Diabetes in America: epidemiology and scope of the problem. Diabetes Care. 1998;21 Suppl 3:C11-C14.

3. King H, Aubert RE, Herman WH. Global burden of diabetes, 1995-2025: prevalence, numerical estimates, and projections. Diabetes Care. 1998;21(9):1414-1431.

4. The Diabetes Atlas. 6th ed [webpage on the Internet]. International Diabetes Federation; 2013. Available from: http://www.idf.org/diabetesatlas. Accessed March 3, 2014.

5. Donahoe SM, Stewart GC, McCabe CH, et al. Diabetes and mortality following acute coronary syndromes. JAMA. 2007;298(7):765-775.

6. Aronson D, Rayfield EJ, Chesebro JH. Mechanisms determining course and outcome of diabetic patients who have had acute myocardial infarction. Ann Intern Med. 1997;126(4):296-306.

7. McGuire DK, Emanuelsson H, Granger CB, et al. Influence of diabetes mellitus on clinical outcomes across the spectrum of acute coronary syndromes. Findings from the GUSTO-IIb study. GUSTO IIb Investigators. Eur Heart J. 2000;21(21):1750-1758.

8. Malmberg K, Yusuf S, Gerstein HC, et al. Impact of diabetes on long-term prognosis in patients with unstable angina and non-Q-wave myocardial infarction: results of the OASIS (Organization to Assess Strategies for Ischemic Syndromes) Registry. Circulation. 2000;102(9): 1014-1019.

9. Go AS, Mozaffarian D, Roger VL, et al; American Heart Association Statistics Committee and Stroke Statistics Subcommittee. Heart disease and stroke statistics - 2013 update: a report from the American Heart Association. Circulation. 2013;127(1):e6-e245.
10. Duarte R, Castela S, Reis RP, et al. Acute coronary syndrome in a diabetic population - risk factors and clinical and angiographic characteristics. Rev Port Cardiol. 2003;22(9):1077-1088.

11. Herlitz J, Wognsen GB, Emanuelsson H, et al. Mortality and morbidity in diabetic and nondiabetic patients during a 2-year period after coronary artery bypass grafting. Diabetes Care. 1996;19(7):698-703.

12. Johansen OE, Birkeland KI, Orvik E, et al. Inflammation and coronary angiography in asymptomatic type 2 diabetic subjects. Scand J Clin Lab Invest. 2007;67(3):306-316.

13. Stone PH. Ischemia dictates outcome, not symptoms. J Am Coll Cardiol. 2013;61:712-713

14. Pan WH, Cedres LB, Liu K, et al. Relationship of clinical diabetes and asymptomatic hyperglycemia to risk of coronary heart disease mortality in men and women. Am J Epidemiol. 1986;123(3):504-516.

15. Lew WY, DeMaria AN. Diabetes and coronary disease: a need for new therapies for an expanding disease burden. $J$ Am Coll Cardiol. 2013;61(20):2046-2047.

16. Preis SR, Hwang SJ, Coady S, et al. Trends in all-cause and cardiovascular disease mortality among women and men with and without diabetes mellitus in the Framingham Heart Study, 1950 to 2005. Circulation. 2009;119(13):1728-1735.

17. Mellbin LG, Anselmino M, Rydén L. Diabetes, prediabetes and cardiovascular risk. Eur J Cardiovasc Prev Rehabil. 2010;17 Suppl 1: S9-S14.

18. Valensi P, Lorgis L, Cottin Y. Prevalence, incidence, predictive factors and prognosis of silent myocardial infarction: a review of the literature. Arch Cardiovasc Dis. 2011;104(3):178-188.

19. Davis TM, Coleman RL, Holman RR; UKPDS Group. Prognostic significance of silent myocardial infarction in newly diagnosed type 2 diabetes mellitus: United Kingdom Prospective Diabetes Study (UKPDS) 79. Circulation. 2013;127(9):980-987.

20. Harris GD, White RD. Exercise stress testing in patients with type 2 diabetes: When are asymptomatic patients screened? Clin Diabetes. 2007;25(4):126-130.

21. Hachamovitch R, Hayes SW, Friedman JD, Cohen I, Berman DS. Comparison of the short-term survival benefit associated with revascularization compared with medical therapy in patients with no prior coronary artery disease undergoing stress myocardial perfusion single photon emission computed tomography. Circulation. 2003;107(23):2900-2907.

22. Raggi P, Shaw LJ, Berman DS, Callister TQ. Prognostic value of coronary artery calcium screening in subjects with and without diabetes. J Am Coll Cardiol. 2004;43(9):1663-1669.

23. Raff GL, Gallagher MJ, O'Neill WW, Goldstein JA. Diagnostic accuracy of noninvasive coronary angiography using 64-slice spiral computed tomography. J Am Coll Cardiol. 2005;46(3):552-557.

24. Greenwood JP, Maredia N, Younger JF, et al. Cardiovascular magnetic resonance and single-photon emission computed tomography for diagnosis of coronary heart disease (CE-MARC): a prospective trial. Lancet. 2012;379(9814):453-460.

25. Phillips DJ, de Kretser DM, Hedger MP. Activin and related proteins in inflammation: not just interested bystanders. Cytokine Growth Factor Rev. 2009;20(2):153-164.

26. Naka T, Nishimoto N, Kishimoto T: The paradigm of IL-6: from basic science to medicine. Arthritis Res. 2002;4(Suppl 3):S233-S242.

27. Danesh J, Kaptoge S, Mann AG, et al. Long-term interleukin-6 levels and subsequent risk of coronary heart disease: two new prospective studies and a systematic review. PLoS Med. 2008;5(4):e78.

28. Hingorani AD, Casas JP. The interleukin-6 receptor as a target for prevention of coronary heart disease: a mendelian randomisation analysis. Lancet. 2012;379(9822):1214-1224.

29. Ofstad AP, Gullestad L, Orvik E, et al. Interleukin-6 and activin A are independently associated with cardiovascular events and mortality in type 2 diabetes: the prospective Asker and Bærum Cardiovascular Diabetes (ABCD) cohort study. Cardiovasc Diabetol. 2013; $12: 126$. 
30. American Diebetes Association. Standards of medical care in diabetes - 2012. Diabetes Care. 2012;35 Suppl 1:S11-S63.

31. Greenland P, Alpert JS, Beller GA, et al. 2010 ACCF/AHA guideline for assessment of cardiovascular risk in asymptomatic adults: a report of the American College of Cardiology Foundation/American Heart Association Task Force on Practice Guidelines. $J$ Am Coll Cardiol. 2010;56(25):e50-e103.

32. Waugh N, Black C, Walker S, McIntyre L, Cummins E, Hillis G. The effectiveness and cost-effectiveness of computed tomography screening for coronary artery disease: systematic review. Health Technol Assess. 2006;10(39):iii-iv, ix-x, 1-41.

33. Fihn SD, Gardin JM, Abrams J. ACCF/AHA/ACP/AATS/PCNA/ SCAI/STS guideline for the diagnosis and management of patients with stable ischemic heart disease: a report of the American College of Cardiology Foundation/American Heart Association Task Force on practice guidelines, and the American College of Physicians, American Association for Thoracic Surgery, Preventive Cardiovascular Nurses Association, Society for Cardiovascular Angiography and Interventions, and Society of Thoracic Surgeons. J Am Coll Cardiol. 2012;60:e44-e164.

34. Chaitman BR, Laddu AA. Stable angina pectoris: antianginal therapies and future directions. Nat Rev Cardiol. 2012;9:40-52.

35. Lacoste LL, Théroux P, Lidón RM, Colucci R, Lam JY. Antithrombotic properties of transdermal nitroglycerin in stable angina pectoris. Am J Cardiol. 1994;73(15):1058-1062.

36. Berges A, Van Nassauw L, Timmermans JP, Vrints C. Role of nitric oxide during coronary endothelial dysfunction after myocardial infarction. Eur J Pharmacol. 2005;516(1):60-70.

37. Bøttcher M, Madsen MM, Randsbaek F, et al. Effect of oral nitroglycerin and cold stress on myocardial perfusion in areas subtended by stenosed and nonstenosed coronary arteries. Am J Cardiol. 2002;89(9): 1019-1024.

38. Henderson RA, O'Flynn N. Management of stable angina: summary of NICE guidance. Heart. 2012;98(6):500-507.

39. Jahangir A, Terzic A. K(ATP) channel therapeutics at the bedside. J Mol Cell Cardiol. 2005;39(1):99-112.

40. IONA Study Group. Effect of nicorandil on coronary events in patients with stable angina: the Impact Of Nicorandil in Angina (IONA) randomised trial. Lancet. 2002;359(9314):1269-1275.

41. Fox K, Garcia MA, Ardissino D, et al. Guidelines on the management of stable angina pectoris: executive summary: The Task Force on the Management of Stable Angina Pectoris of the European Society of Cardiology. Eur Heart J. 2006;27:1341-1381.

42. Malmberg K, Herlitz J, Hjalmarson A, Ryden L. Effects of metoprolol on mortality and late infarction in diabetics with suspected acute myocardial infarction. Retrospective data from two large studies. Eur Heart J. 1989;10(5):423-428.

43. Kjekshus J, Gilpin E, Cali G, Blackey AR, Henning H, Ross J Jr. Diabetic patients and beta-blockers after acute myocardial infarction. Eur Heart J. 1990;11:43-50.

44. Fonseca VA. Effects of beta-blockers on glucose and lipid metabolism. Curr Med Res Opin. 2010;26:615-629.

45. Théroux P, Taeymans Y, Morissette D, Bosch X, Pelletier GB, Waters DD. A randomized study comparing propranolol and diltiazem in the treatment of unstable angina. J Am Coll Cardiol. 1985;5(3):717-722.

46. Parodi O, Simonetti I, Michelassi C, et al. Comparison of verapamil and propranolol therapy for angina pectoris at rest: a randomized, multiple-crossover, controlled trial in the coronary care unit. Am J Cardiol. 1986;57(11):899-906.

47. Nissen SE, Tuzcu EM, Libby P, et al. Effect of antihypertensive agents on cardiovascular events in patients with coronary disease and normal blood pressure: the CAMELOT study: a randomized controlled trial. JAMA. 2004;292(18):2217-2225.

48. Gersh B, Braunwald E, Rutherford J. Chronic coronary artery disease. In: Braunwald E, editor. Heart Disease. 5th ed. Philadelphia, Pa: WB Saunders Co; 1997:307-335.
49. Heidenreich PA, McDonald KM, Hastie T, et al. Meta-analysis of trials comparing beta-blockers, calcium antagonists, and nitrates for stable angina. JAMA. 1999;281(20):1927-1936.

50. Tapp RJ, Sharp A, Stanton AV, et al. Differential effects of antihypertensive treatment on left ventricular diastolic function an ASCOT (Anglo-Scandinavian Cardiac Outcomes Trial) substudy. J Am Coll Cardiol. 2010;55(17):1875-1881.

51. Sossalla S, Maier LS. Role of ranolazine in angina, heart failure, arrhythmias, and diabetes. Pharmacol Ther. 2012;133:311-323.

52. DeQuattro V, Skettino S, Chaitman BR, et al. Comparative antianginal efficacy and tolerability of ranolazine in diabetic and nondiabetic patients: Results of the MARISA trial. J Am Coll Cardiol. 2001;37(2):A338.

53. Chaitman BR, Pepine CJ, Parker JO, et al. Effects of ranolazine with atenolol, amlodipine, or diltiazem on exercise tolerance and angina frequency in patients with severe chronic angina: a randomized controlled trial. JAMA. 2004;291(3):309-316.

54. Stone PH, Gratsiansky NA, Blokhin A, Huang IZ, Meng L. Antianginal efficacy of ranolazine when added to treatment with amlodipine: the ERICA (Efficacy of Ranolazine in Chronic Angina) trial. $J$ Am Coll Cardiol. 2006;48(3):566-575.

55. Scirica BM, Morrow DA, Hod H, et al. Effect of ranolazine, an antianginal agent with novel electrophysiological properties, on the incidence of arrhythmias in patients with non ST-segment elevation acute coronary syndrome results from the Metabolic Efficiency With Ranolazine for Less Ischemia in Non-ST-Elevation Acute Coronary Syndrome-Thrombolysis in Myocardial Infarction 36 (MERLIN-TIMI 36) randomized controlled trial. Circulation. 2007;116(15):1647-1652.

56. Kosiborod M, Arnold SV, Spertus JA, et al. Evaluation of ranolazine in patients with type 2 diabetes mellitus and chronic stable angina: results from the TERISA randomized clinical trial (Type 2 Diabetes Evaluation of Ranolazine in Subjects With Chronic Stable Angina). J Am Coll Cardiol. 2013;61(20):2038-2045.

57. Lamendola P, Nerla R, Pitocco D, et al. Effect of ranolazine on arterial endothelial function in patients with type 2 diabetes mellitus. Atherosclerosis. 2013;226:157-160.

58. Anselmino M, Ohrvik J, Ryden L. Resting heart rate in patients with stable coronary artery disease and diabetes: a report from the euro heart survey on diabetes and the heart. Eur Heart J. 2010;31:3040-3045.

59. Miot A, Ragot S, Hammi W, et al. Prognostic value of resting heart rate on cardiovascular and renal outcomes in type 2 diabetic patients: a competing risk analysis in a prospective cohort. Diabetes Care. 2012;35(10):2069-2075.

60. Borer JS, Tardif JC. Efficacy of ivabradine, a selective I(f) inhibitor, in patients with chronic stable angina pectoris and diabetes mellitus. Am J Cardiol. 2010;105(1):29-35.

61. Beautiful Study Group; Ferrari R, Ford I, Fox K, Steg PG, Tendera M. BEAUTIFUL study: randomized trial of ivabradine in patients with stable coronary artery disease and left ventricular systolic dysfunctionbaseline characteristics of the study population. Cardiology. 2008;110(4):271-282.

62. Marzilli M. Does trimetazidine prevent myocardial injury after percutaneous coronary intervention? Nat Clin Pract Cardiovasc Med. 2008;5(1):16-17.

63. Chazov EI, Lepakchin VK, Zharova EA, et al. Trimetazidine in Angina Combination Therapy - the TACT study: trimetazidine versus conventional treatment in patients with stable angina pectoris in a randomized, placebo-controlled, multicenter study. Am J Ther. 2005;12(1):35-42.

64. Hoogwerf BJ, Young JB. The HOPE study. Ramipril lowered cardiovascular risk, but vitamin E did not. Cleve Clin J Med. 2000;67(4): 287-293.

65. Yusuf S, Sleight P, Pogue J, Bosch J, Davies R, Dagenais G. Effects of an angiotensin-converting-enzyme inhibitor, ramipril, on cardiovascular events in high-risk patients. The Heart Outcomes Prevention Evaluation Study Investigators. N Engl J Med. 2000;342(65):145-153. 
66. Daly CA, Fox KM, Remme WJ, Bertrand ME, Ferrari R, Simoons ML. The effect of perindopril on cardiovascular morbidity and mortality in patients with diabetes in the EUROPA study: results from the PERSUADE substudy. Eur Heart J. 2005;26:1369-1378.

67. ONTARGET Investigators, Yusuf S, Teo KK, et al. Telmisartan, ramipril, or both in patients at high risk for vascular events. $N$ Engl J Med. 2008;358:1547-1559.

68. Herings RM, de Boer A, Stricker BH, Leufkens HG, Porsius A. Hypoglycaemia associated with use of inhibitors of angiotensin converting enzyme. Lancet. 1995;345:1195-1198.

69. Morris AD, Boyle DI, McMahon AD, et al. ACE inhibitor use is associated with hospitalization for severe hypoglycemia in patients with diabetes. Diabetes Care. 1997;20(9):1363-1367.

70. Chapman MJ, Ginsberg HN, Amarenco P, et al. Triglyceride-rich lipoproteins and high-density lipoprotein cholesterol in patients at high risk of cardiovascular disease: evidence and guidance for management. Eur Heart J. 2011;32(11):1345-1361.

71. Miller M, Stone NJ, Ballantyne C, et al. Triglycerides and cardiovascular disease: a scientific statement from the American Heart Association. Circulation. 2011;123(20):2292-2333.

72. Barter P, Gotto AM, LaRosa JC, et al. HDLcholesterol, very low levels of LDL cholesterol and cardiovascular events. N Engl J Med. 2007;357: 1301-1310.

73. Baigent C, Blackwell L, Emberson J, et al. Efficacy and safety of more intensive lowering of LDL cholesterol: a meta-analysis of data from 170,000 participants in 26 randomised trials. Lancet. 2010;376: $1670-1681$.

74. Scott R, O'Brien R, Fulcher G, et al. Effects of fenofibrate treatment on cardiovascular disease risk in 9,795 individuals with type 2 diabetes and various components of the metabolic syndrome: the Fenofibrate Intervention and Event Lowering in Diabetes (FIELD) study. Diabetes Care. 2009;32(3):493-498.

75. ACCORD Study Group, Ginsberg HN, Elam MB, et al. Effects of combination lipid therapy in type 2 diabetes mellitus. $N$ Engl J Med. 2010;362(17):1563-1574.

76. Taskinen MR, Barter PJ, Ehnholm C, et al. Ability of traditional lipid ratios and apolipoprotein ratios to predict cardiovascular risk in people with type 2 diabetes. Diabetologia. 2010;53(9):1846-1855.

77. Mills EJ, O'Regan C, Eyawo O, et al. Intensive statin therapy compared with moderate dosing for prevention of cardiovascular events: a metaanalysis of 40,000 patients. Eur Heart J. 2011;32:1409-1415.

78. Baigent C, Keech A, Kearney PM, et al. Efficacy and safety of cholesterol-lowering treatment: prospective meta-analysis of data from 90,056 participants in 14 randomised trials of statins. Lancet. 2005;366: 1267-1278.

79. Kearney PM, Blackwell L, Collins R, et al. Efficacy of cholesterollowering therapy in 18,686 people with diabetes in 14 randomised trials of statins: a meta-analysis. Lancet. 2008;371:117-125.

80. Armitage J. The safety of statins in clinical practice. Lancet. 2007; 370(9601):1781-1790.

81. Catapano AL, Reiner Z, De Backer G, et al. ESC/EAS Guidelines for the management of dyslipidaemias: the Task Force for the management of dyslipidaemias of the European Society of Cardiology (ESC) and the European Atherosclerosis Society (EAS). Atherosclerosis. 2011; 217 Suppl 1:S1-S44.

82. Preiss D, Seshasai SR, Welsh P, et al. Risk of incident diabetes with intensive-dose compared with moderate-dose statin therapy: a metaanalysis. JAMA. 2011;305:2556-2564.

83. Ferroni P, Basili S, Falco A, Davi G. Platelet activation in type 2 diabetes mellitus. J Thromb Haemost. 2004;2(8):1282-1291.

84. Natarajan A, Marshall SM, Worthley SG, Badimon JJ, Zaman AG. The presence of coronary artery disease increases platelet-dependent thrombosis in patients with type 2 diabetes mellitus. J Thromb Haemost. 2008;6(12):2210-2213.

85. Osende JI, Badimon JJ, Fuster V, et al. Blood thrombogenicity in type 2 diabetes mellitus patients is associated with glycemic control. $\mathrm{J} \mathrm{Am}$ Coll Cardiol. 2001;38(5):1307-1312.
86. Viswanathan GN, Marshall SM, Schechter CB, Balasubramaniam K, Badimon JJ, Zaman AG. Thrombus and antiplatelet therapy in type 2 diabetes mellitus. A prospective study after non-ST elevation acute coronary syndrome and a randomised, blinded, placebo-controlled study in stable angina. Thromb Haemost. 2012;108(5):937-945.

87. Antithrombotic Trialists' Collaboration; Collaborative meta-analysis of randomized trials of antiplatelet therapy for prevention of death, myocardial infarction, and stroke in high risk patients. $B M J$. 2002;324(7329): 71-86.

88. Rydén L, Grant PJ, Anker SD, et al. ESC Guidelines on diabetes, pre-diabetes, and cardiovascular diseases developed in collaboration with the EASD: the Task Force on diabetes, pre-diabetes, and cardiovascular diseases of the European Society of Cardiology (ESC) and developed in collaboration with the European Association for the Study of Diabetes (EASD). Eur Heart J. 2013;34(39):3035-3087.

89. Inzucchi SE, Bergenstal RM, Buse JB, et al. Management of hyperglycaemia in type 2 diabetes:a patient-centered approach. Position statement of the American Diabetes Association (ADA) and the European Association for the Study of Diabetes (EASD). Diabetologia. 2012;55(6):1577-1596.

90. Wilson PW, D’Agostino RB, Levy D, Belanger AM, Silbershatz H, Kannel WB. Prediction of coronary heart diseaseusing risk factor categories. Circulation. 1998;97(18):1837-1847.

91. Kvaavik E, Batty GD, Ursin G, Huxley R, Gale CR. Influence of individual and combined health behaviors on total and cause-specific mortality in men and women: The United Kingdom health and lifestyle survey. Arch Intern Med. 2010;170(8):711-718.

92. Yu-Poth S, Zhao G, Etherton T, Naglak M, Jonnalagadda S, Kris-Etherton PM. Effects of the national cholesterol education program's step I and step II dietary intervention programs on cardiovascular disease risk factors. a meta-analysis. Am J Clin Nutr. 1999;69(4):632-646.

93. Warnick GR, Myers GL, Cooper GR, Rifai N. Impact of the third cholesterol report from the Adult Treatment Panel of the National Cholesterol Education Program on the clinical laboratory. Clin Chem. 2002;48(1):11-17.

94. Kones R. Recent advances in the management of chronic stable angina II. Anti-ischemic therapy, options for refractory angina, risk factor reduction, and revascularization. Vasc Health Risk Manag. 6:749-774.

95. Alderman EL, Kip KE, Whitlow PL, et al. Native coronary disease progression exceeds failed revascularization as cause of angina after five years in the Bypass Angioplasty Revascularization Investigation (BARI). J Am Coll Cardiol. 2004;44:766-774.

96. Hlatky MA, Boothroyd DB, Bravata DM, et al. Coronary artery bypass surgery compared with percutaneous coronary interventions for multivessel disease: a collaborative analysis of individual patient data from ten randomised trials. Lancet. 2009;373:1190-1197.

97. Rana JS, Venkitachalam L, Selzer F, et al. Evolution of percutaneous coronary intervention in patients with diabetes: a report from the National Heart, Lung, and Blood Institute-sponsored PTCA (1985-1986) and Dynamic (1997-2006) Registries. Diabetes Care. 2010;33(9):1976-1982.

98. Wijns W, Kolh P, Danchin N, et al. The Task Force on Myocardial Revascularisation of the European Society of Cardiology (ESC) and the European Association for Cardio-Thoracic Surgery (EACTS). Guidelines on myocardial revascularization. Eur Heart J. 2010;31(20): 2501-2555.

99. Sobel BE, Frye R, Detre KM. Burgeoning dilemmas in the management of diabetes and cardiovascular disease: rationale for the Bypass Angioplasty Revascularization Investigation 2 Diabetes (BARI 2D) Trial. Circulation. 2003;107(4):636-642.

100. Marso SP. Revascularization trumps medicine for patients with type 2 diabetes mellitus and chronic angina (or does it?). Circulation. 2011;123(14):1489-1491.

101. Farkouh ME, Domanski M, Sleeper LA, et al. Strategies for multivessel revascularization in patients with diabetes. $N$ Eng J Med. 2012;367(25):2375-2384. 
102. Kapur A, Hall RJ, Malik IS, et al. Randomized comparison of percutaneous coronary intervention with coronary artery bypass grafting in diabeticpatients. 1-year results of the CARDia (Coronary Artery Revascularization in Diabetes) trial. J Am Coll Cardiol. 2010;55(5): 432-440.

103. Kappetein AP, Feldman TE, Mack MJ, et al. Comparison of coronary bypass surgery with drug-eluting stenting for the treatment of left main and/or three-vessel disease: 3-year follow-up of the SYNTAX trial. Eur Heart J. 2011;32(17):2125-2134.

104. Banning AP, Westaby S, Morice MC, et al. Diabetic and nondiabetic patients with left main and/or 3-vessel coronary artery disease: comparison of outcomes with cardiac surgery and paclitaxel-eluting stents. J Am Coll Cardiol. 2010;55:1067-1075.

105. Kappetein AP, Head SJ, Morice MC, et al. Treatment of complex coronary artery disease in patients with diabetes: 5-year results comparing outcomes of bypass surgery and percutaneous coronary intervention in the SYNTAX trial. Eur J Cardiothorac Surg. 2013;43(5):1006-1013.

106. Sedlis SP, Morrison DA, Lorin JD, et al. Percutaneous coronary intervention versus coronary bypass graft surgery for diabetic patients with unstable angina and risk factors for adverse outcomes with bypass: outcome of diabetic patients in the AWESOME randomized trial and registry. J Am Coll Cardiol. 2002;40:1555-1566.

107. Hannan EL, Wu C, Walford G, et al. Drug-eluting stents vs coronaryartery bypass grafting in multivessel coronary disease. $N$ Engl J Med. 2008;358:331-341.

108. Weintraub WS, Grau-Sepulveda MV, Weiss JM, et al. Comparative effectiveness of revascularization strategies. N Eng J Med. 2012;366: 1467-1476.
109. Kim WJ, Park DW, Yun SC, et al. Impact of diabetes mellitus on the treatment effect of percutaneous or surgical revascularization for patients with unprotected left main coronary artery disease: a subgroup analysis of the MAIN-COMPARE study. JACC Cardiovasc Interv. 2009;2:956-963.

110. Hakeem A, Garg N, Bhatti S, Rajpurohit N, Ahmed Z, Uretsky BF. Effectiveness of percutaneous coronary intervention with drug-eluting stents compared with bypass surgery in diabetics with multivessel coronary disease: comprehensive systematic review and meta-analysis of randomized clinical data. J Am Heart Assoc. 2013;2(4):e000354.

111. Perk J, De Backer G, Gohlke H, et al. European Guidelines on cardiovascular disease prevention in clinical practice (version 2012). The Fifth Joint Task Force of the European Society of Cardiology and Other Societies on Cardiovascular Disease Prevention in Clinical Practice (constituted by representatives of nine societies and by invited experts). Eur Heart J. 2012;33(13):1635-1701.

112. Kohler M, Stradling JR. Mechanisms of vascular damage in obstructive sleep apnea. Nat Rev Cardiol. 2010;7(12):677-685.

113. Kohler M, West S, Stradling J. Diabetes in obstructive sleep apnea. Am J Respir Crit Care Med. 2010;182(2):286-287.

114. Nutrition recommendations and interventions for diabetes: a position statement of the American Diabetes Association. Diabetes Care. 2008;31 Suppl 1:S61-S78.

115. Estruch R, Ros E, Salas-Salvadó J, et al; PREDIMED Study Investigators. Primary prevention of cardiovascular disease with a Mediterranean diet. N Engl J Med. 2013;368(14):1279-1290.
Research Reports in Clinical Cardiology

\section{Publish your work in this journal}

Research Reports in Clinical Cardiology is an international, peerreviewed, open access journal publishing original research, reports, editorials, reviews and commentaries on all areas of cardiology in the clinic and laboratory. The manuscript management system is completely online and includes a very quick and fair peer-review system.

\section{Dovepress}

Visit http://www.dovepress.com/testimonials.php to read real quotes from published authors. 